\title{
O POSTULADO DA RAZOABILIDADE E O DIREITO DO TRABALHO
}

\author{
THE POSTLLATE OF REASONABLENESS AND LABUR LAW
}

\section{Marcus Orione Gonçalves Correia"}

\begin{abstract}
Resumo:
O racionalismo é movimento que tomou conta da humanidade, com destaque especial para o Iluminismo. A racionalidade iluminista é baseada na idéia da razão, em contraposição à irracionalidade da fé do misticismo. O racionalismo do Direito não coincide necessariamente com a racionalidade de outros ramos do conhecimento humano.
\end{abstract}

Palavras-chave: Razoabilidade. Diretos Sociais. Interpretação evolutiva. Direitos fundamentais sociais.

\begin{abstract}
:
Rationalism is a movement that held mankind, with a special emphasis to Iluminism. Iluminist rationality is based on the idea of reason, in opposition to the irrationality of faith of mysticism. The rationalism of law does not necessarily coincide with the rationality of other human knowledge branches.
\end{abstract}

Keywords: Reasonability. Social Rights. Evolutive Interpretation. Social Fundamental Rights.

1. Conceituando a razoabilidade (e a proporcionalidade)

Trataremos do postulado da razoabilidade e de sua aplicação aos direitos sociais em geral e aos trabalhistas em particular.

$\mathrm{Na}$ realidade. nos mais vários instantes em que se lida com norma. se exigiria do operador do Direito a atuação razoável e proporcional. Assim, ela está presente no momento da confecção da norma pelo legislador. bem como no instante em que realiza a sua interpretação (seja por um advogado, por um administrador ou por um juiz).

A razoabilidade e a proporcionalidade, portanto, são postulados informativos da atuação constante de todos que de alguma forma têm contato com a equação do Direito. Em termos mais simplistas, seria possível afirmar-se que até mesmo o destinatário da norma deve-se postar diante dela de forma a obter uma solução razoável e proporcional para a sua situação no caso concreto. Inobstante, em geral, estes

Doutor e Livre-docente em Direito pela Faculdade de Direito da Universidade de São Paulo. Professor Associado do Departamento de Direito do Trabalho e da Seguridade Social da Faculdade de Direito da Universidade de São Paulo. Professor do programa de Pós-Graduação em Dircitos Humanos da USP. Professor da Escola Paulista de Direito Social. Juiz. Federal.<ericabc@terra.com.br>. 
postulados têm sido estudados sob a ótica daqueles que produzem ou interpretam a norma jurídica na operação jurídica, subtraídos aqui os destinatários. Portanto, exige que se utilizem da razoabilidade e da proporcionalidade na sua atuação, em geral, os legisladores, os juízes e os administradores (já que atualmente a legalidade estrita não se tem apresentado como suficiente para a adequada atuação destes últimos).

Aqui, analisaremos particularmente a razoabilidade na atuação judicial. No entanto, como já dissemos alhures, o Judiciário não deve ser entendido como produto final, a partir apenas da atividade do juiz em si mesmo. Judiciário é poder do povo, na medida em que é mais ou menos manifestação de poder quanto mais se encontra inserido na mente popular como instituição eficiente na distribuição da Justiça, entendida esta como serviço público essencial. Portanto, a razoabilidade no plano judicial começa, sim. com o conhecimento e capacidade de interpretação do Direito pelo destinatário, que é quem irá comover a atuação em juizo - dela abdicando se não-compreender os seus direitos e, quando isto ocorre, menos legitimação a idéia de Judiciário possui. A razoabilidade judicial tem início também na atuação coerente e consistente dos advogados, que são aqueles que primeiro interpretam a norma para a tomada de posições também - embora não apenas - perante o Judiciário, podendo, pois, extrair desta norma maior ou menor efetividade. Se o advogado consegue interpretar com a razoabilidade a norma, extraindo de suas finalidades maior proteção social, v.g., certamente o juiz terá maior espaço para atuar.

E a proporcionalidade? Como fica nestas ponderações? Qual o seu espaço?

Particularmente, embora existam entendimentos em sentido contrário, acreditamos que não há, utilizada a lógica do Direito, como se ser proporcional sem se ser razoável. Portanto, a razoabilidade conduz à proporcionalidade ou proporcionalidade é expressão do que é razoável para o Direito. Chegamos a esta consideração pelos seguintes motivos.

A razoabilidade, embora seja muito mais do que racionalidade, não deixa de ser, em grande parte, expressão do racionalismo que tomou conta do mundo moderno. Assim, embora o razoável possa defluir de um sentimento de justiça, para que possa ser compreendido passa quase que constantemente por uma lógica típica da racionalidade. Basta vermos a estrutura lógica com que se trata, no Direito, a razoabilidade. Esta, como se verá, nada mais é do que a consubstanciação de uma fórmula de lógica formal, assim reduzida: diante de diversos meios, utiliza-se aquele que possa melhor atingir a finalidade da norma, com menor desgaste a outros meios possíveis de serem utilizados. Inobstante, como veremos a seguir, mesmo o sentimento de justiça pode ser absorvido 
por uma fórmula de natureza racional, para evitar incertezas que confrontariam a noção de segurança jurídica.

Na linha acima, a razão do Direito não se contenta com as razões que se Ihe são externas, embora delas possa se valer para chegar ao seu desiderato. Assim, a racionalidade do Direito é uma e a da economia, por exemplo, é outra. Assim. se as racionalidades são distintas, as razoabilidades também o serão. O racionalismo é movimento que tomou conta da humanidade, com especial destaque para o iluminismo. A racionalidade iluminista, que ainda permeia muito da nossa existência hodierna, é baseada na idéia da razão - em contraposição à irracionalidade da fé, do misticismo. Ora, nesta perspectiva, somente há racionalismo onde há razão. Logo, a razão é expressão que acompanha o racionalismo, e, portanto, em grande parte no mundo moderno, a razoabilidade. Não bastam razões espúrias, mas sim aquelas que logicamente poderiam satisfazer a necessidade humana de obter respostas concretas. Há que se buscar razões intelectualmente acolhidas. No entanto, restaria um problema: para a equação do Direito não basta intelectualidade. Soluções inteligentes podem não ser soluções juridicamente acolhidas. Por exemplo, o controle de natalidade pode parecer, sob a perspectiva intelectual, arma interessante ao combate da pobreza. Pode parecer racional determinar à força, e pelo uso simples do direito positivo, o controle de natalidade. Mas, ao redundar em supressão da liberdade e mesmo da igualdade, tal medida pode parecer intelectualmente razoável, para o atingimento de determinado fim (ex.: controle de gastos públicos), não sendo, inobstante, juridicamente razoável. Logo, o racionalismo do Direito, ou melhor a sua razoabilidade, não coincide necessariamente com a racionalidade de outros ramos do conhecimento humano. E, aqui, o que chamamos acima de senso de justiça na realidade, será outra coisa, também absorvida pela racionalidade. Isto se justifica de forma simples: o racionalismo do Direito, o seu traço distintivo, está na busca do ideal de liberdade/igualdade. Logo, a razão, no direito, deverá sempre tender para a igualdade - tanto que as grandes teorias da Justiça sempre se relacionam com a discussão da igualdade. Portanto, somente é razoável a solução que, no Direito, prestigiar a igualdade. Somente é razoável a solução que, no Direito, prestigiar a proporcionalidade. Entendendo-se proporcionalidade como expressão da igualdade, na medida em que somente se possibilita tratar desigualmente os desiguais na proporção de sua desigualdade, esta nada mais seria do que a razoabilidade do Direito. Assim, não vemos utilidade na distinção entre razoabilidade e proporcionalidade.

Resumindo, a razoabilidade (já incluída na noção a idéia de proporcionalidade), no caso de atuação judicial, é postulado de interpretação para todos os que lidam com a norma a ser interpretada - destinatário, advogados, serventuários, 
agentes do Ministério Público e juizes das diversas instâncias. É claro que o nosso conceito pode parecer mais amplo do que aquele que é normalmente sugerido pela doutrina em geral. No entanto. parece-nos que a razoabilidade, ao buscar a essência do direito enquanto manifestação cultural em constante formação, deve ser postulado básico de atuação de toda a sociedade para as relações humanas a serem reguladas (e para a sua compreensão).

Devemos sempre frisar que a razão do Direito é diferente da razão de outras entidades culturais com os quais a humanidade está em contato. Assim, o racionalismo no Direito é expressão do racionalismo de humanidade. No entanto. supera a simples equação do racional para uma equação do racional da justiça. Sendo a noção de justiça tida muito mais sob a perspectiva do sentimento do que da razão, a única forma, entendemos de the dar racionalidade, é pela expressão objetiva da igualdade/liberdade. Liberdade e igualdade, aqui, seriam expressões de uma mesma realidade. Somente haverá igualdade material onde houve liberdade de escolhas. A igualdade tem o seu sentido material, mas também a liberdade deve ser vista sob a perspectiva material. Assim, não basta garantir nos textos legais a igualdade (igualdade formal). ela deve existir no mundo dos fatos e deve nortear também as soluções jurídicas. Da mesma forma, não há apenas que se garantir a liberdade nas leis (liberdade formal), há que se dar efetividade nas relações humanas (liberdade material). Igualdade/liberdade formal não é suficiente para garantir igualdade/liberdade material. A razuabilidade na atuação judicial deve portanto buscar, na interpretação do Direito. a igualdade/liberdade material.

Concluindo esta parte de nossa análise, a razoabilidade, na atuação judicial, é postulado de interpretação de todos os envolvidos na solução do conflito. norteado pela igualdade/liberdade material.

2. Entendendo a importância da razoabilidade para os direitos sociais

Para que possamos trabalhar com o postulado da razoabilidade nos direitos sociais em geral, e no Direito do Trabalho em particular, urge que conceituemos os direitos sociais.

$\Lambda$ expressão Direito Social, para designar um ramo do Direito, foi, no nosso país, muito utilizada por Cesarino Júnior. Para este renomado autor, os direitos sociais - em especial o Direito do Trabalho e Previdenciário estariam ligados à proteção do hipossuficiente. No entanto, a hipossuficiência, para Cesarino, se confundiria apenas com um estado de sujeição econômica. A respeito confira-se o seguinte trecho: 
A exprussão Direito Social, assim como Legislação Social. incidem na arguição de que todo direito é naturalmente social, por isso que não pode haver direito senão em sociedade: Ubi societas, ibi jus. A ela respondem os seus partidários. observando que a expressão 'social', na denominação da nossa disciplina, visa opô-la ao direito individualista, oriundo da Revolução Francesa, significando a predominância do interesse coletivo sobre o individual. Pensamos que têm razão, embora 'todo direito' hoje sc socialize, ou melhor, se penetre de um sentido social, como tão bem têm demonstrado, entre outros, os professores Le Fur. Josserand e Radbruch. É que apesar do sentido social, da 'humanização do Direito', ser comum a todos os seus ramos. esse sentido social se acentuou sobremodo, diriamos até, se concuntrou neste ramo do conhecimento jurídico a que uns chamam Legislação e outros, melhormente, Direito Social. (...)

Ademais, visando êste ramo do Direito, como veremos logo mais, ao abordarmos seu conceito, restabelecer o equilibrio 'social', muito lógico nos parece que se the dê exatamente êste qualificativo de 'Social', uma ve\% que todo equívoco desaparece, dado o sentido especial que a palavra tem atualmente.

Com razão diz Fantini: 'Tôda a legislação do Estado pode dizer-se social. Mas imprópriamente dizendo legislação social se entendeu dizer e se continua a entender aquela particular legislação que se retere aos trabalhadores i às classes mais necessitadas'.

Arcá define a Legislação Social: 'o conjunto de normas emanadas do Estado, disciplinando as relaçōes que intercedem entre as classes capitalistas e as classes trabalhadoras', acrescentando: 'Social se diz essa lcgislação, seja porque se refere a relações entre classes ou entre individuos de classe diversa, seja porque não tem atitudes, caracteres, e fins jurídicos, mas sim de tutela e proteção. de disciplinamento de situações de fato e de relações sociais extrajudiciais, as quais superam e em parte contradizem a premissa da absoluta igualdade de direito, que é imprescindivel à compruensão das rúlações judiciais de direito privado e a noção de súdito, que também é imprescindivel à compruensão das relações que prendem o indivíduo de qualquer classe ao Estado" :

Por outro lado, na interessante obra de George Gurvitch percebe-se. quando do delineamento da concepção de Direito Social, a presença constante da idéia

CESARINO JÚNIOR, Antonio Ferreira. Direito social brasileiro. Rio de Janeiro/São Paulo: Livraria Freitas Bastos. 1963. p. 30-31. 
de relação de subordinação (em oposição à coordenação, típica dos direitos individuais) e da defesa dos interesses por entidades associativas. ${ }^{2}$

No entanto. cremos que, em especial com o advento da Constituição Federal de 1988, a hipossuficiência econômica destacada não bastaria como elemento diferencial dos direitos sociais. Aliás, sequer a redução do conceito a ramos como o Direito do Trabalho e da Seguridade Social seria suficiente. Atualmente, a abrangência subjetiva e objetiva dos direitos sociais é extremamente maior. Assim, estes não se caracterizariam, no nosso entender, como uma categoria distinta dos direitos público e privado, mas permeariam ambos nos instantes em que ocorressem traços comuns distintivos e que necessitassem de ser tratados, sob a perspectiva da proteção social maximizada. Expliquemos: pode haver Direito Social tanto em áreas tradicionalmente afetas ao Direito Privado (exemplo clássico seria o Direito do Trabalho, mas teríamos também a sua incidência sobre certas relações de consumo ou aquelas estabelecidas por pequenos contratantes do sistema financeiro de habitação) ou também ao Direito Público (como exemplo tradicional tem-se o Direito Previdenciário, mas também seria possível a sua constatação no Direito Sanitário ou no Direito Tributário).

Portanto, os princípios e postulados dos direitos sociais podem nortear tanto relações de Direito Privado, quanto de Direito Público, havendo apenas que se dimensionar, no âmbito destes. quando aquele se encontre presente.

A presença seria indicada. acreditamos, pela presença de uma situação de hipossuficiência (estado jurídico), que não seria necessariamente econômica. Não há necessidade, portanto. de uma relação de hipossuficiência (relação jurídica) que protraia no tempo, bastado uma situação ou estado de sujeição decorrente de uma inferioridade, ainda que momentânea, que reduz o homem a uma condição desumana. Trata-se de uma sujeição que diminui toda e qualquer condição referente ao estado de humanidade. É claro que em um país pobre como Brasil. no mais das vezes, esta sujeição acaba defluindo de uma sujeição econômica, embora isto não seja indispensável.

Tomemos, como exemplo, uma situação em que alguém. embora não sendo pobre, não tenha recursos suficientes para cobrir o tratamento de saúde que salvaria a sua vida. Esta pessoa se encontra em "status" de sujeição, ainda que momentânea, que a inviabiliza a percepção de sua concretização como ser humano. Portanto, aqui, para que possa se concretizar enquanto ser humano, fará "jus" à proteção social ligada ao Direito Sanitário (concessão de remédios, pagamento pelo poder público de tratamento - se este não existir na rede pública -, etc.).

A respeito confira-se a belissima obra GURVITCH, George. L'idée du droit social. Librairie du Recueil Sirey: Paris. 1932. 
Da mesma forma, em uma relação de consumo, a pessoa pode não ser pobre, mas a complexidade empresarial moderna sugere a proteção, com técnicas as mais diversas de proteção social (ex.: inversão do ônus da prova nos casos admitidos pelo ordenamento jurídico).

Outra peculiariedade que merece ser destacada é a amplitude das hipóteses de direitos sociais previstas constitucionalmente. $\mathrm{O}$ art. $6^{\circ}$ da Constituição Federal é extremamente abrangente, dizendo ser Direito Social tanto o direito à moradia. quanto o direito ao lazer, passando pelo Direito ao Trabalho e de previdência social. Aqui na verdade, entendemos, apenas se encontram enumerados, para fins de programa, aqueles que são direitos inicialmente indispensáveis para a concretização da condição humana na sociedade. No entanto, certamente podem ser dimensionados, também, sob a perspectiva de que hipossufiências de "status" a eles relacionadas devem imediatamente merecer do Legislador (e mesmo dos membros dos demais Poderes) atenção redobrada.

A idéia de hipossuficiência de "status" na forma como exposta anteriormente deixa clara a relevância que a razoabilidade tem para os direitos sociais. Ora, é da essência dos direitos sociais que o Direito apareça como instrumento de equalização entre as partes. Logo, nos direitos sociais a noção de Direito é potencializada, na medida em que a sua racionalidade (igualdade/liberdade) é elemento essencial para a concretização dos direitos sociais. Como dito, a racionalidade do Direito está informada essencialmente pela noção de igualdade/liberdade. Logo, sendo a igualdade/liberdade o vetor dos direitos sociais, é aqui que a racionalidade do Direito, informada pela razão do justo/igual/livre, mostrará a sua plenitude.

Por outro lado, em se tratando de Direito em constante formação, os direitos sociais se valem, como nenhum dos demais direitos, da metodologia de interpretação que acreditamos ser essencialmente fincada no postulado da razoabilidade: a interpretação evolutiva.

3. Entendendo a conexão entre a razoabilidade, a interpretação evolutiva e os direitos sociais

A interpretação evolutiva consiste, sinteticamente, em uma metodologia de interpretação que busca a constante "reinvenção" do Direito para os fatos cotidianos. especialmente a partir de uma releitura constitucional. Assim, não precisaríamos ficar em constante estado assemblear constituinte, bastando que os diversos operadores do Direito fiquem atentos às modificações da sociedades e do sentido de igualdade/liberdade. para a adequação dos princípios constitucionais aos anseios sociais. É interpretação. portanto, 
que finca as suas raizes nos princípios constitucionais e na sua adequação ao constante movimento da sociedade. Para muitos, trata-se de expressão do conhecido póspositivismo.

Se de um modo geral, a interpretação evolutiva é importante para os diversos direitos constitucionalmente apostos, é da própria essência dos direitos sociais que a interpretação do Direito seja evolutiva. Aguardar-se a confecção de normas jurídicas, mormente de natureza constitucional, para a constante realização do pacto em torno dos direitos sociais, redundaria, em última análise, em perigo constante para a evolução das relações em sociedade. Portanto, todos os operadores do Direito, inclusive os seus destinatários, devem buscar uma interpretação das normas de forma a fazer o direito evoluir no sentido da sociedade ideal (dever-ser do Direito).

A racionalidade jurídica, portanto, está na igualdade/liberdade constantemente renovada no pacto da constituição real. Os direitos sociais são a mais digna expressão desta assertiva.

Para melhor elucidar, nada melhor do que alguns exemplos de interpretação evolutiva.

De ninguém é desconhecido que situação das companheiras evoluiu no direito de forma a thes propiciar maior proteção jurídica. No começo, no Direito Civil brasileiro, a proteção jurídica centrava-se apenas na instituição do casamento e, de alguma forma, buscava invalidar qualquer forma de união que conspirasse contra esta figura. A sociedade percebia no casamento uma dimensão e a ele atribuía dimensão jurídica, protegendo-o até mesmo contra formas "espúrias" que pudessem atentar contra a sagrada noção de família baseada na idéia de casamento. Os tempos mudaram e as companheiras passam a ser admitidas no cotidiano do nosso povo: os "casais casados" cedem espaço para os "casais não-casados" (companheiros). Atento à realidacle fática, o Direito precisou evoluir, mesmo sem norma específica de proteção, no âmbito do Direito de Família, dos companheiros. Os julgados começam a conceder direitos, fora do âmbito do Direito de Família. considerando os companheiros como empregados, em um primciro momento, e como sócios de uma socicdade de fato, em um outro momento distinto. No caso do Dircito Previdenciário, a partir daí, surgem as primciras leis de proteção das concubinas, concedendo-lhes pensões. Mais tarde, como o Direito em geral passa a dar efeitos a esta modalidade de relação, o Direito Constitucional c o Direito Civil passam a admitir a proteção, a partir da noção de união estável, com a previsão de direitos de familia. Da desproteção à proteção, foram vários anos e embates dos atores envolvidos, até que o Dircito de Família (e a própria noção de família) passasse a ser afetada. A interpretação evolutiva se deu de forma clara no caso em apreço, sendo que. 
quanto mais os atores envolvidos, se deram conta da necessidade de mobilização, mais conseguiram do Direito respostas.

Estamos sendo participes de uma situação semelhante, que vem tendo o mesmo traçado. A proteção aus direitos dos homoal’etivos, que está em plena formação. O Direito Previdenciário. aqui e novamente, dá mostras de que esta união tem efeitos, com decisão judicial, que determinou a concessão de pensão por morte a companheiro homoafetivo. Será que o caminho a ser traçado vai ser o mesmo? Certamente, a força da vida e dos grupos dirá com o tempo.

Nos direitos sociais. esta evolução é ainda mais nítida. Os exemplos que daremos nos diversos quadros abaixo, concernentes aos direitos trabalhistas, mostrarão como esta assertiva é plena de verdade.

É claro que a razoabilidade. da forma como conceituada acima. é pustulado indispensável sem o qual esta evolução não pode ser processada.

A razoabilidade, enquanto expressão da igualdade/liberdade, é elemento modulador da evolução do próprio Direito. O Direito somente consegue se concretizar. como dito. na medida em que mais efetiva a medida do justo/livre/igual. A evolução do Direito é portanto a evolução da sociedade nesta direção (do justo/livre/igual). Logo, somente utilizando-se da razoabilidade o Direito consegue. em todas as suas expressões, alcançar o seu destino.

4. Entendendo a dinâmica da interpretação evolutiva e seus vários instrumentais

A interpretação evolutiva. portanto. tem na razoabilidade o seu elemento modulador. Portanto, não se evolui no Direito sem razoabilidade (postulado que edifica um sistema jurídico de justiça/liberdade/igualdade).

Logo, há que se entender, no exercício cotidiano da prática judicial, como a razoabilidade deve ser construída, para se entender como a evolução se processa.

Deve-se entender. ainda, que a irracionalidade também pode ser força contra-evolutiva, a permear, infelizmente, as construções judiciais. Ou seja: da mesma forma que existe uma força evolutiva que tende à igualdade, há uma resistência conservadora, que busca evitar o progresso da interpretação evolutiva. No entanto, sob pena de ilegitimidade do Judiciário, a evolução. creio, tem apenas a sua consecução retardada. mas não-inviabilizada. A busca pela igualdads, necessariamente - mais cedo ou mais tarde - fará com que a resistência seja impelida para tora do sistema juridico. A este fenômeno, costumo chamar, quando perputrada na atuação do Juiz. de interpretação involutiva. 
No entanto, como nos interessa aqui a interpretação evolutiva e o papel da razoabilidade na sua construção, passemos a chamar atenção para os diversos métodos que podem ser utilizados para otimizar os seus resultados. Na realidade, a jurisprudência já vem utilizando estes métodos, muitas das vezes, sem perceber, mesmo, que vem fazendo uso da interpretação evolutiva. Tentaremos, portanto, apenas sistematizar os instrumentos necessários para os que pretendem fazer o uso da razoabilidade, para a construção de interpretação evolutiva - em particular para os direitos sociais e, mais especificamente, para os trabalhistas.

Primeiro, devemos entender que, para sermos razoáveis, devemos optar, dentre os diversos meios oferecidos, por aquele que, uma vez escolhido, seja o mais apto para se atingir determinado fim, com o menor prejuízo possível aos valores veiculados pelos meios preteridos. Há que se atingir um fim a partir da lógica dos fatos, mas também a partir da lógica do Direito (justiça/igualdade/liberdade).

Do conceito acima, percebe-se que a razoabilidade envolve um esquema relativamente simples de lógica formal -- não se exaurindo, no entanto, nesta. Assim, há apenas que se buscar, na situação em apreço, o motivo determinante, os meios e o fim a se alcançar. Assim, diante de um determinado motivo, vários meios podem-se apresentam para a obtenção de um determinado fim. Os meios devem ser aptos, sob a perspectiva da lógica dos fatos e da lógica do Direito (maior do que o simples silogismo), para a obtenção do fim. Diante dos vários meios apostos, há que se escolher o mais eficiente - lógica e juridicamente - para a consecução da finalidade pretendida.

Exemplificando: a) motivo: elevação dos índices de AIDS: b) fím: diminuição ou eliminação dos elevados índices de AIDS; c) meios sugeridos: c. 1) controle da distribuição de bebidas alcoólicas; c.2) política de distribuição de camisinhas e c.3) proibição de sexo entre homens e mulheres. A questão é a seguinte: dos meios apresentados, qual o mais apto ao atingimento do fim almejado, com menor impacto sobre os princípios constitucionais envolvidos? Certamente, que o primeiro meio controle de bebidas alcoólicas - não é sequer apto imediatamente para se alcançar o fím colimado. Carece, pois, de pertinência lógica (considerada a lógica dos fatos mesmo). Já os dois outros meios podem, sob a perspectiva da lógica dos fatos, se revelar aptos para que se atinja o fim de eliminação ou diminuição dos índices de AIDS. No entanto, ao se escolher o segundo meio (distribuição de camisinhas) em detrimento do último (proibição de sexo entre homens e mulheres) buscou-se a preservação mesmo da lógica constitucional. O meio escolhido não-afronta postulados constitucionais, sendo que a redução da liberdade se justifica - não sendo impingida qualquer solução que redunde em diminuição das igualdades. Outra seria a conclusão se qualquer limitação fosse feita 
apenas a um grupo de risco (por exemplo, os homoafetivos). A desigualdade, e portanto a ausência de razoabilidade, seria patente! Por fim. repare-se que o último meio (proibição de sexo), apesar de ser apto logicamente para atingir o fim desejado, redunda em uma restrição que afronta uma prerrogativa mesmo de humanidade. Logo, não é um meio juridicamente lógico, já que afronta postulados constitucionais de liberdade (no sentido material). A escolha por uma política de distribuição de camisinhas, dentre os diversos meios oferecidos, é a mais razoável já que é a que mais se aproxima da proporcionalidade. preservando, dentre todas, de forma efetiva, a igualdade material. Logo, a razoabilidade por si só conduz ao tratamento proporcional, pela escolha sempre do meio que mais iguala todos os envolvidos na situação proposta.

Como veremos no momento oportuno, estas situações se apresentam também para os direitos sociais, e para o Direito do Trabalho em particular. Na realidade, quando se escolhe, dentre os vários meios, o mais razoável, está a se realizar um cotejo ligado à própria questão constitucional do confronto de princípios constitucionais - já que os meios, ligados a um determinado fim. têm embutida, no mais das vezes, a tensão revelada entre os princípios constitucionais. Portanto, a razoabilidade envolve, no mais das vezes, a discussão do conflito de princípios. Em direitos sociais, esta questão é extremamente relevante, sendo a ponderação uma constante do raciocinio - muitas vezes, sequer percebidas pelos agentes envolvidos no processo de interpretação. A respeito desta questão teremos oportunidade de mais detalhar no item seguinte. O que merece, por ora, ser destacado é que o conflito de princípios deve ser resolvido de forma a conformar as opçôes de unidade constantes do texto constitucional. Portanto, há que se fugir de falácias comuns neste processo de interpretação.

Inicialmente, colhe evitar que opções pessoais suplantem as opções constitucionais. Logo, por mais que se deseje ideologizar um ramo do Direito, a questão é de ideologia do sistema constitucional. O nosso sistema constitucional é capitalista e, infelizmente, sobrevive às custas da propriedade privada. Na contramão desta tendência. buscando solução diametralmente oposta, não há que se transformar os direitos sociais em lugar nenhum. Os direitos sociais existem e são direitos fundamentais - e enquanto tal devem ser tratados. Assim. tendo havido um máximo de proteção social na Constituição Social não há como se transformar esta em uma opção por minimos. A virtude do intérprete do Direito Social é a busca da maior quantidade de proteção social possivel em sistema capitalista, utilizando das estruturas constitucionais dos direitos sociais apostos na Constituição de 1988. A racionalidade não é ideológica pessoal. mas de ideologia constitucional, que, por ser jurídica, é expressão do máximo possível de 
justiça social/igualdade/liberdade. Nos exemplos especificos dos direitos sociais, abaixo elencados, isto ficará bem nítido.

No conflito de princípios, portanto, não será possivel que a propriedade privada já saia ganhando dos demais princípios, uma vez que conflita com vários outros, como o da função social da propriedade e da própria liberdade em sentido material. A propriedade privada não foi destruída em um sistema capitalista admitido na Constituição de 1988, mas foi redesenhada ali mesmo e em textos posteriores (como é o caso do novo Código (ivil). Portanto, a liberdade formal e a propriedade privada não são sobreprincípios. Se pudermos admiti-los, os únicos sobreprincípios seriam o da dignidade da pessoa humana - intimamente ligados ao da liberdade material/igualdade material. No entanto, mesmo estes últimos se não forem admitidos como sobreprincípios, devem ser admitidos como postulados de interpretação (já que a dignidade da pessoa humana é fundamento da República Federativa do Brasil, como se percebe do art. $3^{\circ}$ da Constituição Federal). Portanto, em conflito de princípios, a dignidade/liberdade material/igualdade material será clemento balizador da razoabilidade - já que o Direito busca a igualdade/liberdade, que, em último instância, se confundem com a própria idéia de dignidade da pessoa humana, no nosso entender. Para compreender e criar um conceito de dignidade da pessoa humana, é indispensável que esta seja livre para ser igual. É necessário, diz o professor Dalmo de Abreu Dallari, citando Pico Della Mirândola. que o homem seja "faber sui" - construtor de si mesmo. Para que o homem possa inventar-se a si mesmo, é necessário que tenha liberdade para fazê-lo em plenas condições de igualdade com os demais. Logo, qualquer conflito de princípios, para que se inclua em uma solução razoável, deve ser analisado a partir destas premissas. Os princípios conflitam entre si, mas nunca com a dignidade da pessoa humana diretamente - já que esta baliza a solução razoável.

A razoabilidade, observados os parâmetros acima, é, pois, indispensável para a consecução dos objetivos de justiça social constantes dos direitos sociais. No entanto, não é o único elemento a ser vislumbrado em uma interpretação evolutiva que deve ser considerado. Por outro lado, a razoabilidade pode existir mesmo quando não há interpretação evolutiva inobstante, será importante elemento construtor desta dinâmica de interpretação.

Entendemos que a interpretação evolutiva. ao buscar a razoabilidade jurídica (justiça/igualdade/liberdade). deve. para alcançar o seu intento, estar muito mais ligada à essência do que à forma. A essência do justo/igual/livre não se encontra necessariamente no texto da lei embora possa estar contido neste, não havendo como se fazer um inicial discurso contrário às regras -, mas sim nos principios. Portanto, os 
princípios, enquanto expressão da unidade politico-jurídico constitucional. devem ser sempre lidos à luz da própria evolução da sociedade. Não se cuer dizer aqui que o sistema jurídico deva ser subserviente ao político ou econômico -- já que se tratam de sistemas diferentes e como tais devem ser tratados. Inobstante, não há como se fazer evolução. por interpretação jurídica, sem a percepção da evolução dos fatos da sociedade: a busca do justo/igual/livre passa por uma observação também das relações sociais. Logo. algumas regras podem abandonar o sistema jurídico não porque foram revogadas por outra, mas porque não há que se sustentar a sua sobrevivência à luz da interpretação constitucional - e não apenas da constituição formal, mas sim da constituição real (consubstanciada nus princípios e suas relações com a sociedade e as inovações daí provenientes, por exemplo, em novas regras, etc.). Afinal, se a letra mata. o espirito vivifica ...

Por outro lado, é necessário, em interpretação evolutiva, especialmente no que concerne aos direitos sociais, que a força normativa da Constituição se dê com o máximo de efetividade. Assim. além das condições materiais para a existência dos direitos sociais, faz-se indispensável que as normas constitucionais revestidas da célebre expressão "nos termos da lei" sejam concretizadas, ainda que por meio da interpretação. Não há evolução onde a própria Constituição conteve previsão a respeito de direitos sociais que dependem eternamente de uma previsão legal, que nunca é efetivada. Assim, a expressão "nos termos da Lei" passa a ser lida como "nos termos do Direito" devendo ser implementada a partir de uma leitura constitucional dos princípios e das disposições já existentes para situações outras que envolvem o conceito em jogo. Logo, a interpretação evolutiva pretende dar força normativa à Constituição e como tal deve ser encarada.

$\mathrm{Na}$ interpretação evolutiva, há ainda que se dar o máximo de efetividade aos instrumentais jurídicos que garantam substrato para os direitos fundamentais - e, no nosso caso, para os direitos fundamentais sociais. Logo, a instrumentalização/instrumentalidade é a própria expressão da razoabilidade na procedimentalização do Estado Democrático de Direito. $O$ princípio da instrumentalidade, muito usado pelos processualistas, nada mais é do que uma expressão da razoabilidade. Somente instrumentos efetivos na busca da igualdade dos que se utilizam do poder constitucional de ação serão. no âmbito judicial, capazes de ajudar a superar deficiências de forma que inviabilizariam a solução justa do conflito. Fm sintese e de forma simples, de nada adiantaria a interpretação evolutiva em juizo se o procedimento inviabilizasse o seu alcance. Na sua vertente judicial, a interpretação com razoabilidade se houver o total desimpedimento para que todos obtenham da manifestação final do Estado a respeito do litígio posto em juízo, em especial 
desobstruindo a via que se lhes é oferecida, qual seja o processo. Aqui vale lembrar Bobbio, para quem o problema não é mais o do conceito dos direitos humanos, mas dos meios para instrumentalizar o seu exercício. Logo, a interpretação evolutiva não pode subsistir sem a existência de mecanismos que facilitem ao invés de obstar - a manifestação judicial.

Em síntese, para a interpretação evolutiva, em juizo, devemos destacar os seus mais diversos métodos, quais sejam:

a) é interpretação que envolve a razoabilidade, com especial destaque para a colisão de princípios:

b) é interpretação que busca dar força normativa à constituição. dando eficácia a situações, mesmo sem a edição de lei regulamentar;

c) é interpretação que permite a extensão de direitos fundamentais, alargando o seu campo de atuação;

d) é interpretação $\mathrm{tm}$ que os próprios meios devem ser reinventados para que se possibilite a manifestação razoável do Judiciário.

Com todas as premissas assentadas para a efetivação da interpretação evolutiva, passamos a utilizar esta técnica nos direitos sociais como meio indispensável à sobrevivência deste ramo do Direito.

5. Compreendendo a razoabilidade como construtora da interpretação evolutiva em direitos sociais - com especial destaque de situações envolvendo os direitos trabalhistas. Uma análise do método a partir de casos concretos

Passamos, para melhor explicitar o método da interpretação evolutiva nos direitos sociais, passamos a trabalhar com vários casos concretos. A solução destes casos revelará os meandros da construção, para os direitos sociais, do raciocínio que envolve o uso desta tipo de interpretação, com especial destaque para a análise da razoabilidade.

Inicialmente, há que se destacar que estes casos foram selecionados para cursos de pós-graduação lato sensu em Direito do Trabalho. Foi feita uma seleção de hipóteses que guardam relação entre si, a partir de uma premissa constante. Por outro lado. considerados na sua totalidade, os casos revelam conexão a partir da idéia de que todos se consubstanciam em interpretação evolutiva de direitos sociais. São eles: 


\begin{tabular}{|c|c|c|c|}
\hline Colisāo de princípios & $\begin{array}{l}\text { Falta de regulamentaçāo } \\
\text { legal para a hipótese } \\
\text { prevista na Constituição }\end{array}$ & $\begin{array}{l}\text { Técnica de extensāo dos Direitos } \\
\text { Fundamentais }\end{array}$ & \begin{tabular}{|l|} 
Questōes \\
procedimentais que \\
efetivam os Direitos \\
Sociais \\
\end{tabular} \\
\hline $\begin{array}{l}\text {-Princípio da Intimidade } \\
\text { "versus" Propriedade nos } \\
\text { casos de monitoramento } \\
\text { de e-mail do trabalhador. } \\
\text { Direito ao trabalho } \\
\text { "versus" direito de } \\
\text { propriedade no caso de } \\
\text { cláusula de não } \\
\text { concorrência } \\
\text { Validade (TRT } 2^{\text {a Região }} \\
\text { - R.O. 2003-03.10.762- } \\
\text { Relator Sérgio Pinto } \\
\text { Martins }\end{array}$ & $\begin{array}{l}\text {-Art. } 7^{\circ}, \text { XXIII da } \\
\text { CF/1988: Atividades } \\
\text { penosas, na forma da lei. } \\
\text {-Art. 37, VII da CF } \\
\text { 1988, Lei n. } 8.036 / 90 . \\
\text { art. 20, XIV: Greve no } \\
\text { serviço público, na } \\
\text { forma de lei especifica. }\end{array}$ & $\begin{array}{l}\text {-Alcoolismo crônico c } \\
\text { inexistência da justa causa do } \\
\text { art. 482, f CLT TST ERR } \\
\text { 320/99. I } \\
\text { (Relator Ministru Dalazen). } \\
\text { - Levantamento do FGTS: } \\
\text { Ampliação das Hipóteses de } \\
\text { levantamento. } \\
\text { - Reintegração de Trabalhador } \\
\text { com AIDS. }\end{array}$ & $\begin{array}{l}\text { - Prescrição no } \\
\text { Direito do Trabalho: } \\
\text { leitura do art. } 7^{\circ} \\
\text { XXIX, CF/1988. } \\
\text { - Leitura do art. } 8^{\circ} \text {, } \\
\text { III. CF/I988 - } \\
\text { ampliação das } \\
\text { hipoteses de } \\
\text { substituição } \\
\text { processual pelos } \\
\text { sindicatos. } \\
\text {-Ampliação da } \\
\text { competencia da } \\
\text { Justiça do Trabalho } \\
\text { pela E.C. } 45 / 04 .\end{array}$ \\
\hline
\end{tabular}

Aqui, percebe-se que houve um agrupamento em quatro situações distintas - todas ligadas entre si pelo fato de revelarem interpretação evolutiva. Passemos a analisar cuidadosamente cada uma delas:

1) Colisão de princípios

$\mathrm{Na}$ primeira hipótese, há o conflito de princípios que envolve a escolha dos meios mais adequados. Trata-se de questões envolvendo a razoabilidade. A primeira situação ali arrolada é realmente emblemática para a compreensão do tema. O monitoramento do e-mail do trabalhador certamente é meio invasivo do Direito à intimidade. No entanto, não há como se desprestigiar o direito de propriedade neste caso, podendo ser utilizado outro meio - menos prejudicial à intimidade - que proteja a propriedade. Assim, por exemplo, seria meio que conciliaria os dois valores a vedação, por meio eletrônico, de acesso a determinados sites. Esta vedação não-implica afronta à intimidade e prestigia a propriedade privada, dos meios de produção - que, por vivermos em um sistema capitalista, não pode ser desprezada. O monitoramento, portanto, invade, em qualquer hipótese, o direito à intimidade, o mesmo não se dando com a vedação mencionada. Logo, há meios mais efetivos de se proteger a propriedade sem se atentar contra os demais direitos fundamentais. O meio eleito (monitoramento) causa maior prejuízo à intimidade ... que está naturalmente mais próxima da dignidade/igualdade/liberdade - do que a vedação de acesso a determinados sitios. Logo, deve ser sempre descartado. O mesmo cuidado deve ser tomado com a segunda situação explicitada. As cláusulas de não-concorrência embutem o conflito entre a propriedade da 
empresa dos meios de produção (propriedade intelectual no caso) e a liberdade de trabalhar. A segunda se encontra muito mais próxima da estrutura dignidade/igualdade material/liberdade material do que a primeira. Portanto, mesmo a indenização pode não ser suficiente, dada a natureza essencial à existência humana do direito ao trabalho privar um homem de trabalhar, por qualquer dinheiro que seja, afeta, no mundo moderno, a sua própria existência. se tratando, pois, de direito de personalidade. de direito existencial.

2) Falta de regulamentação legal para a hipótese prevista na Constituição

A segunda hipótesc revela uma das mais difíceis e menos accitas formas de se realizar a interpretação evolutiva. No entanto, quando realizada, conduz a uma maior força normativa da Constituição. O trabalho penoso, por exemplo, atenta contra Direito Fundamental Social - e não apenas contra este, mas também contra direitos fundamentais individuais, como a proteção à vida. A ausência de lei regulamentadora acaba por determinar a completa ausîncia da sua força normativa. Logo, há que se buscar no Direito elementos suficientes para a construção do conceito e das conseqüências da sua admissão, mesmo sem lei específica regulamentadora. Veja-se, por exemplo, que, no Direito do Trabalho, já existem os adicionais de periculosidade e de insalubridade. Por exclusão, o conceito de trabalho penoso não coincidiria com estas noções. No entanto. poderia. v.g., extrair componentes, para a sua construção, de conceitos de Direito Previdenciário, onde existe a noção de trabalho penoso, para fins de aproveitamento de tempo especial. Logo, há elementos na legislação, e mesmo na jurisprudência, suficientes à construção do conceito, devolvendo a força normativa a dispositivo constitucionalmente previsto. O mesmo se daria com a greve no setor público, que não foi regulamentada por lei especifica. No entanto, mesmo assim, estas greves continuam a existir, desafiando a falta de regulamentação. Em geral, aqui há dois princípios em conflito: o direito de greve do trabalhador $X$ interesse público na manutenção do serviço público. Ambos são igualmente importantes para a construção da dignidade igualdade material/liberdade material. Portanto. um meio adequado, v.g., seria a possibilidade de greve, com a preservação do mínimo de atendimento para as situações realmente graves, como já prevê a atual lei de greve para os casos de serviços essenciais. O que não se pode é simples acoimar a greve de ilegal (inconstitucional), porque falta lei específica regulamentando. A vedação do direito de greve no serviço público, por inexistència de lei regulamentadora, atenta contra o núcleo du Direito Fundamental em si, não merecendo ser considerado à luz da boa doutrina constitucional. 
Técnica de extensão dos direitos fundamentais

Aqui, seja pela inclusão, seja pela exclusão, adaptou-se u sistema à realidade dos fatos e dos postulados constitucionais referentes aos direitos fundamentais. Assim, por exemplo, considerando o anacronismo da possibilidade de justa causa envolvendo o alcoolismo, o julgado de Relatoria do ministro Dallazen afastou a "letra fria da lei" (art. 482, "f". da CLT). Este caso é exemplo claro de interpretação que mostra a evolução da análise desta doença e do reposicionamento de seu tratamento no mundu juridico. As outras hipóteses (extensão das situações de liberação do FGTS e da garantia de estabilidade para o portador de AIDS) revelam que a extensão - não a analogia, já que não se trata disto - de direitos sociais fundamentais, para a preservação do postulado da igualdade material/liberdade material.

4) Questões procedimentais que efetivam os direitos sociais cm geral, e os trabalhistas em particular

A última hipótese revela que, sem a potencialização dos procedimentos, toda a construção anterior é insuficiente para a consolidação da razoabilidade e da evolução judicial. O excesso de formalismo c a vedação de ingresso cm juizo é, por si só, atentado contra a razoabilidade. Não há razoabilidade onde o instrumento inviabiliza a diç̧ão, pelo Judiciário, do meio mais adequado para que se possa alcançar o fim desejado constitucionalmente. Assim, qualquer amesquinhamento da leitura da legitimação extraordinária do sindicato, como se tentou fazer pela hoje revogada Súmula n. 310 do TST, significa redução da possibilidade de que as lides sejam apreciadas e sua decisão razoável pelo Judiciário possa se efetivar. Ora, sabendo-se que as renúncias são constantes no Direito do Trabalho, em decorrência especialmente do temor natural do empregado da perda de seu posto de trabalho durante o curso da relação de emprego. é comum a abdicação, por estes e individualmente, de postulações que redundariam em ganho, se apreciadas pelo Judiciário, para a igualdade material/liberdade material. Ao se possibilitar a legitimação ao sindicato de forma extraordinária e generalizada, ganham os direitos fundamentais a possibilidade de, sem a renúncia. redundar na interpretação mais razoável de situações que jamais iriam ao Judiciário. O próprio sindicato passa a ser agente estratégico na construção do melhor conceito de Judiciário. Da mesma forma, a ampliação excessiva da competência da Justiça do Trabalho - ou de interpretações neste sentido - podem inviabilizar a atuação deste ramo do Judiciário na solução dos conflitos entre capital e trabalho. Além disto. ao se ver invadida por conflitos com morfologia própria (ex.: de I)ireito Público ou de defesa do consumidor). a Justiça do Trabalho pode 
perder a sua essência e seu postulado máximo que, ainda é, o de lidar com normas de Direito material de proteção do trabalhador. Logo, os meios e as formas podem estimular, ou não, o caminho da razoabilidade, já que não há motivo jurídico para que estes sejam impeditivos da implementação de uma atuação judicial tendente à efetivação dos direitos fundamentais (sociais ou individuais).

Feitas estas considerações em nossas aulas, solicitamos aos nossos alunos do curso de especialização da Faculdade de Direito da USP (turmas 2005/2006) que sugerissem, de sua prática diária. outras hipóteses semelhantes. Para a preservação da autoria das situações propostas, na primeira coluna foram introduzidos os nomes dos discentes. Passemos, agora. a esta rclação:

\begin{tabular}{|c|c|c|c|c|}
\hline & Colisão de principios & $\begin{array}{l}\text { Técnica de extensão } \\
\text { dos Direitos } \\
\text { Fundamentais }\end{array}$ & $\begin{array}{|lr|}\text { Falta } & \text { de } \\
\text { regulamentação para a } \\
\text { hipótese prevista na } \\
\text { Constituição } \\
\end{array}$ & \begin{tabular}{|l|} 
Questōes \\
procedimentais que \\
efetivam os Direitos \\
Sociais
\end{tabular} \\
\hline $\begin{array}{l}\text { GRLPO I: } \\
\text { Marcelo } \\
\text { Jacoto, } \\
\text { Natália } \\
\text { Sgarbi dos } \\
\text { Santos e } \\
\text { Paola Pagani }\end{array}$ & $\begin{array}{l}\text { Entrevistas } \\
\text { admissionais em } \\
\text { que a liberdade de } \\
\text { contratar encontra } \\
\text { limites nos } \\
\text { princípios da } \\
\text { intimidade e } \\
\text { privacidade do } \\
\text { trabalhador, desta } \\
\text { forma algumas } \\
\text { perguntas não } \\
\text { poderão ser feitas } \\
\text { pelo empregador em } \\
\text { potencial. }\end{array}$ & $\begin{array}{l}\text { Um empregado que } \\
\text { pediu demissão há } \\
\text { menos de um ano e } \\
\text { precisava sacar os } \\
\text { depósitos fundiários } \\
\text { para comprar uma } \\
\text { cadeira de rodas para } \\
\text { seu próprio uso. } \\
\text { Em sentença, o Juiz } \\
\text { deferiu o pedido de } \\
\text { liberação do FGTS, } \\
\text { em liminar, incsmo } \\
\text { não sendo uma das } \\
\text { hipóteses previstas } \\
\text { na Lei n. } 8.036 / 90\end{array}$ & $\begin{array}{l}\text { Jornada de trabalho } \\
12 \times 36 \text {. Construção } \\
\text { jurisprudencial, na } \\
\text { qual é admitida uma } \\
\text { jornada supcrior ao } \\
\text { limite diário ( } 8 \text { horas } \\
\text { diárias). em razão de } \\
\text { maior periodo de } \\
\text { intervalo } \\
\text { intrajornada, } 36 \\
\text { horas de descanso }\end{array}$ & $\begin{array}{l}\text { Doença do trabalho e } \\
\text { acidente do trabalho. } \\
\text { A prescrição bienal } \\
\text { que tem sido adotada } \\
\text { pelus Juizos } \\
\text { trabalhistas não leva } \\
\text { em conta que algumas } \\
\text { seqüelas decorrentes } \\
\text { de tais situações } \\
\text { demoram mais que } \\
\text { dois anos para se } \\
\text { manifestar }\end{array}$ \\
\hline $\begin{array}{l}\text { GRUPO II: } \\
\text { Loopoldina } \\
\text { A.X. de } \\
\text { Medeiros. } \\
\text { João Carlos } \\
\text { L.P. Silva e } \\
\text { Daniel Balam }\end{array}$ & $\begin{array}{l}\text { Revista Íntima e } \\
\text { Câmera de Video = } \\
\text { Propriedade } \\
\text { "versus" Intimidade. }\end{array}$ & $\begin{array}{l}\text { Jurisprudência } \\
\text { redimensionando } \\
\text { textos legais. } \\
\text { Decisão do STJ } \\
\text { conferindo pensão } \\
\text { por morte ao avô que } \\
\text { criou o neto (filho } \\
\text { falecido) como se } \\
\text { fosse "pai"' do } \\
\text { mesmo. } \\
\text { Assim fica } \\
\text { caracterizada a } \\
\text { dependência no } \\
\text { espirito (e não na } \\
\text { letra da lei) do inciso } \\
\text { II, art. 16, Lei n. } \\
8.213 / 9 \mid \text {. }\end{array}$ & $\begin{array}{l}\text { "Na forma da lei": } \\
\text { Constituição Federal } \\
\text { de 1988, art. } 201 \S 4 .^{\circ} \\
\text { (manter o valor real } \\
\text { dos beneficios) e } \$ 12 \\
\text { (inclusão } \\
\text { previdenciária de } \\
\text { trabalhadores de } \\
\text { baixa renda). }\end{array}$ & $\begin{array}{l}\text { Instrumentos de } \\
\text { Direito utilizados para } \\
\text { realizar/efetivar os } \\
\text { Direitos } \\
\text { Fundamentais, mais } \\
\text { especificamente } \\
\text { ligado ao beneficio } \\
\text { assistencial da } \\
\text { LOAS (art. } 20 \text { da Lei } \\
\text { n. } 8.742 / 93)\end{array}$ \\
\hline
\end{tabular}




\begin{tabular}{|c|c|c|c|c|}
\hline $\begin{array}{l}\text { GRUPO III: } \\
\text { Alessandra } \\
\text { lara da } \\
\text { Cunha. } \\
\text { Nicolle Renata } \\
\text { Lapolla Agiar } \\
\text { Andrade e } \\
\text { Murillo César } \\
\text { Buck Muniz }\end{array}$ & $\begin{array}{l}\text { Possibilidade de } \\
\text { revista intima dos } \\
\text { empregados, por } \\
\text { meio de negociação } \\
\text { coletiva. Valores } \\
\text { supostamente em } \\
\text { conflito: direito à } \\
\text { intimidade, direito à } \\
\text { propriedade e } \\
\text { reconhecimento da } \\
\text { validade da } \\
\text { negociação coletiva. }\end{array}$ & $\begin{array}{l}\text { Possibilidade de } \\
\text { recebimento do } \\
\text { seguro desemprego } \\
\text { nos casos de pedido } \\
\text { de demissão. }\end{array}$ & $\begin{array}{l}\text { Art. } 7^{\circ} \text {, inciso I CF. } \\
\text { proteção contra } \\
\text { despedida arbitrária } \\
\text { ou sem justa causa na } \\
\text { forma da lei. } \\
\text { Art. } 7^{\circ} \text {, inciso } \\
\text { XXVII, proteção em } \\
\text { face da automação, } \\
\text { na forma da lei. }\end{array}$ & $\begin{array}{l}\text { 1)Contagem da } \\
\text { prescrição dos } \\
\text { direitos trabalhistas a } \\
\text { partir da data da } \\
\text { extinção do contrato } \\
\text { de trabalho, e não do } \\
\text { ajuizamento da ação. } \\
\text { 2)Atuação do } \\
\text { Ministério Público na } \\
\text { hipótese de dispensa } \\
\text { de dirigente sindical, } \\
\text { em face do direito } \\
\text { coletivo envolvido. }\end{array}$ \\
\hline $\begin{array}{l}\text { GRUPO IV: } \\
\text { Marcelo } \\
\text { Tandlet Paes } \\
\text { Cordeiro, } \\
\text { Roberto } \\
\text { Bellodi, } \\
\text { Roberto } \\
\text { Benovente } \\
\text { Cordeiro }\end{array}$ & $\begin{array}{l}\text { Realização de } \\
\text { biografia não } \\
\text { autorizada: } \\
\text { Oposição dos } \\
\text { herdeiros (direito a } \\
\text { Intimidade) X } \\
\text { direito de } \\
\text { informação. }\end{array}$ & $\begin{array}{l}\text { Interpretação do art. } \\
118, \text { Lei n. } 8.213 / 91 \text {. } \\
\text { Interpretação } \\
\text { gramatical e } \\
\text { restritiva do } \\
\text { dispositivo no } \\
\text { tocante ao prazo } \\
\text { minimo de } \\
\text { estabilidade (sempre } \\
\text { coincidente com um } \\
\text { ano, quando é prazo } \\
\text { minimo e não } \\
\text { definitivo). } \\
\end{array}$ & $\begin{array}{l}\text { Vedação da dispensa } \\
\text { arbitrária, nos termos } \\
\text { da lei. A Constituição } \\
\text { NÃO VEDA. As } \\
\text { verbas indenizatórias } \\
\text { se aplicariam nos } \\
\text { casos previstos } \\
\text { (insuficiência } \\
\text { financeira- } \\
\text { econômica, elc.) nos } \\
\text { demais casos seria } \\
\text { necessário um plus. }\end{array}$ & $\begin{array}{l}\text { Imposição ao } \\
\text { reclamante do } \\
\text { encargo de apresentar } \\
\text { o correto endereço } \\
\text { das empresas } \\
\text { fomecedoras de mão- } \\
\text { de-obra em relação } \\
\text { terceirizada de } \\
\text { trabalho. }\end{array}$ \\
\hline $\begin{array}{l}\text { GRUPO V: } \\
\text { Graciela } \\
\text { Siqueira } \\
\text { Galvão, } \\
\text { Leomar } \\
\text { Botasso Leite } \\
\text { Moreno } \\
\text { Mantini e } \\
\text { Luciana Soares } \\
\text { Azevedo de } \\
\text { Santana }\end{array}$ & $\begin{array}{l}\text { Vedação } \\
\text { constitucional da } \\
\text { equiparação salarial } \\
\text { entre servidoress } \\
\text { públicos. } \\
\text { Principio da } \\
\text { Legalidade (art. 37, } \\
\text { XII, CF vedaria } \\
\text { supostamente a } \\
\text { equiparação) } \\
\text { "versus" Principio } \\
\text { da Isonomia (art. } 5^{\circ} \text {. } \\
\text { caput, CF) }\end{array}$ & $\begin{array}{l}\text { Empregado } \\
\text { Doméstico. Direito } \\
\text { às horas extras. } \\
\text { Deferimento. Art. } 7^{\circ} \text {, } \\
\text { parágrafo único, CF. } \\
\text { não prevê tal } \\
\text { possibilidade eos } \\
\text { tribunais não } \\
\text { concedem, com } \\
\text { supedâneo na norma } \\
\text { constitucional, que } \\
\text { supostamente vedaria } \\
\text { a extensão destes } \\
\text { direitos ao } \\
\text { doméstico. } \\
\text { Fundamento para o } \\
\text { deferimento: } \\
\text { Principio da } \\
\text { igualdade e } \\
\text { dignidade da pessoa } \\
\text { humana. }\end{array}$ & $\begin{array}{l}\text { Proteção } \\
\text { constitucional em } \\
\text { face da automação, } \\
\text { art. } 7^{\circ}, \mathrm{XXVII.} \mathrm{CF.} \\
\text { Ausência de } \\
\text { legislação ordinária } \\
\text { que estabeleça us } \\
\text { limites do exercicio } \\
\text { dessa proteção. }\end{array}$ & $\begin{array}{l}\text { Ações de indenização } \\
\text { por acidente de } \\
\text { trabalho. Aplicação da } \\
\text { prescrição civil em } \\
\text { detrimento da } \\
\text { prescrição trabalhista. }\end{array}$ \\
\hline
\end{tabular}

Passemos a analisar cada uma das propostas realizadas e a sua real introdução na perspectiva da interpretação evolutiva para os direitos sociais. A análise se fará de forma crítica, para que possamos construir melhor as premissas de nosso pensamento. 
I) Colisão de Princípios

a) No caso das entrevistas de admissão, efetivamente haveria que se cuidar para que o teor das perguntas - feitas oralmente ou por escrito - não se revelassem desnecessárias para os fins a que se destinam. Por exemplo, não há razoabilidade em se perguntar se a mulher tem filhos. Fste fato, externo ao ambiente do trabalho, não-revela qualquer utilidade para o desempenho das atividades laborais. A maternidade não é impeditiva de realização de atividades laborais, não-devendo ser impeditiva da obtenção de empregos. É claro que, para certas atividades, algumas perguntas se fazem necessárias: ao se perguntar, para uma candidata ao cargo de comissária de bordo, se esta sofre de claustrofobia, há uma pertinência entre a pergunta realizada e o posto a ser ocupado (trata-se inclusive de pergunta que protege a integridade do próprio postulante ao cargo). No entanto, em hipótese alguma, será possivel a realização de perguntas vexatórias ou outras que imponham ao postulante do posto restrições à sua imagem ou à sua integridade moral. Não há, nestes últimos casos, qualquer conflito e, sim, nítido atentado contra direitos fundamentais individuais do ser humano.

b) No segundo caso, da revista íntima ou da câmera de video, há nítido atentado ao direito de intimidade. Estes meios são completamente inadequados para que se possa atingir a finalidade pretendida. Não há, também, conflito, já que os meios utilizados (câmera ou revista íntima) são completamente inadequados, à luz dos direitos humanos fundamentais. Há outros meios que podem ser utilizados para a punição de trabalhadores que eventualmente cometam o ilícito de se apropriar de bens de propriedade do empregador - como, por exemplo, a utilização de meios processuais adequados para a punição, nas mais diversas esferas. daquele que se apropria do que não pertence (empregado ou-não), já que há figuras próprias tanto no Direito Civil, quanto no Direito Penal.

c) No caso de realização de biografía não autorizada, efetivamente estamos diante de um conflito, que deve ser resolvido, no caso concreto, em favor de uma ou de outra situação. Dependendo do 
grau de invasão à imagem dos autores ou do falecido, há que prevalecer o direito à imagem. Dependendo, no entanto, da hipótese e do interesse na publicação dos dados, deve prevalecer o direito à informação. No entanto, esta hipótese certamente não pertence ao Direito do Trabalho, embora seja de grande utilidade para a compreensão do tema em discussão.

d) Por outro lado, não existe conflito no caso de possibilidade de revista estabelecida por meio de negociação coletiva. $O$ direito coletivo de contratar não se faz a despeito de direitos fundamentais. Assim, por exemplo e na mesma linha, jamais seria possível que a convenção coletiva viabilizasse o direito à escravidão, a partir da perspectiva da autonomia privada coletiva. Da mesma forma no exemplo dado pelos alunos em negociação coletiva que fosse nitidamente restritiva do direito à intimidade, consubstanciando possibilidade vexatória de revista. Não há conflito, na medida em que haveria, isto sim, supressão de um Direito Fundamental pela utilização indevida de outro.

e) A última situação proposta aparentemente revela um cotejo de princípios: o da legalidade "versus" o da isonomia. Diríamos, no entanto, que a legalidade é um aspecto da segurança jurídica formal e isonomia a própria razão de ser da segurança jurídica (materialmente considerada). Logo, o cotejo entre legalidade e isonomia esconde um dos grandes dilemas da modernidade: é possível legalidade sem isonomia? O simples fato de a lei prever aumento para algumas categorias de servidores - ou mesmo para os trabalhadores da iniciativa privada e não para servidores públicos, ou vice-versa é impeditivo da extensão, muitas vezes, pretendidas aos não-destinatários da lei? A questão não é das mais simples, mormente quando vislumbrada à luz da idéia de que a relação entre o Estado e seus servidores, em alguns casos, é estatutária e, no setor privado, a relação é contratual. A assertiva poderia ser infirmada para os servidores celetistas. No entanto, a dúvida permaneceria para a questão de fundo, que é o que importa. Como será obtido o verdadeiro desiderato da igualdade - finalidade última de qualquer segurança juridica deve ser analisado no caso concreto. Assim. a despeito de 
remansosa jurisprudência infirmando esta assertiva, somente a hipótese concreta poderá revelar se a extensão promoveu ou-não a igualdade. Por exemplo, em hipótese semelhante, há determinados servidores que trabalham em condições que, no setor privado, dariam ensejo a uma aposentadoria especial ou ao aproveitamento do tempo como especial. Como, no entanto, jamais veio norma regulamentando a questão, o trabalhador da iniciativa pública ficcará em situação de desamparo. No entanto, a isonomia não sugeriria que o trabalhador que se submete a trabalhos danosos à saúde (frio ou calor excessivos, por exemplo) não deveria ter o mesmo tratamento? Entendemos que sim, mesmo sem norma regulamentadora (situação que analisaremos a seguir). A verdade é uma só: o tratamento desigual, nesta hipótese - assim como em outras de natureza salarial, dependendo do caso -. revela que a legalidade estrita não cumpriu a finalidade da segurança jurídica, qual seja o da igual. Afinal, a lei é prestigiada porque inviabiliza tratamentos desiguais. Com a lei, sabemos que a nossa situação será tratada de forma igual e nunca seremos discriminados. No entanto. no caso em apreço, a leitura restritiva (lei apenas para determinado trabalhador, do setor público ou privado, desprezando-se os demais que se encontram em igualdade de condições) impinge ônus à própria essência da segurança jurídica - bem maior que se pretende aqui defender. Logo, a suposta contradição entre a legalidade e a isonomia revela-se falaciosa, já que a legalidade somente será admitida se estiver a serviço da própria isonomia à qual é sempre servil.

2) Técnicas de extensão dos direitos fundamentais

a) As questões relacionadas às hipóteses de levantamento do FGTS já foram analisadas anteriormente nas hipóteses que já havíamos sugerido anteriormente. No caso em apreço, os alunos sugeriram o levantamento para a compra de cadeira de rodas - o que seria possivel a partir das mesmas premissas já postas anteriormente. Aqui, nitidamente, estaríamos diante de caso de interpretação de que promoveu pela extensão dos direitos fundamentais (se a 
proteção à moradia é um Direito Fundamental, certamente a saúde também o é, como se percebe do rol do art. $6^{\circ}$ da Constituição Federal).

b) A extensão ao avô, promovida pelo STJ, do senefício previsto para o pai no art. 16 da Lei de Benefícios (n. 8.231/91), na realidade, no caso concreto, não se revelou dz.s mais eficientes. A decisão menciona que somente se dá em casos excepcionais e o faz por analogia de situações. No entanto, o conceito constitucional de dependência se revela muito mais eficiente do que a busca, excepcional, da equiparação. Estamos, aqui, diante de situação de Direito Previdenciário, po: óbvio, e nãotrabalhista - no entanto, como se percebe, a técnica, que já temos utilizado constantemente para caso; de direito de segurança social, deve ser confrontada para qualquer situação envolvendo direitos sociais, onde a interp:etação evolutiva revela-se efetivamente ambientada.

c) A extensão das hipóteses do seguro-desemprego também ao desemprego voluntário é propugnada pelo terceiro grupo. Como se sabe a Constituição prevê benefícios previdenciários para o caso de desemprego involuntário (art. 20s, inciso III, da Constituição Federal). Nesta linha, a legislação infraconstitucional pertinente prevê seguro-desemprego para os casos de desemprego involuntário. No entinto, não há na Constituição qualquer proibição para que o desemprego voluntário seja contemplado. Logo, não havendo vedação constitucional, mas apenas indicação de uma das hipóteses de proteção social, nada obstaria a busca de uma rnaior proteção até mesmo ao desemprego voluntário, se tal situação puder ser contemplada pelo "espírito" da Constituição.

d) Não haveria sentido em se limitar a apenas un ano prazo que a Lei não coloca sempre como coincidente a um ano. Aqui sequer estamos diante de caso de interpretação evolutiva, mas sim do seu reverso (que ouso denominar interpretação involutiva - já que para toda idéia de evolução, há a possibilidade de uma idéia oposta de involução). Se a própria lei fala em garantia de estabilidade mínima de um ano ("o segurado que sofreu acidente 
do trabalho tem garantia, pelo prazo mínimo de doze meses, a manutenção do seu contrato de trabalho na empresa" conforme disposição expressa do art. 118 da Lei de Beneficios), não há como se respaldar a jurisprudência que. invariavelmente, considera o prazo como sendo sempre de um ano. A proteção é menor que a possibilitada pela lei, que deveria ser analisada conforme o caso concreto, para o estabelecimento da variação do prazo de estabilidade. A proteção aqui, ao ficar nivelada sempre em um ano, conspira contra a finalidade da norma, que deixou o conteúdo aberto, para melhor atender à hipótese fática que se apresentasse. Não o fazendo, na verdade, os juizes estão diminuindo o nível de proteção, realizando, dependendo do caso, até mesmo, uma interpretação que involui - já que menor que a proteção determinada pela lei, a partir de uma constante que pode não-atender à razoabilidade.

e) O caso do doméstico é bastante esclarecedor. Perceba-se que o par. único do art. $7^{\circ}$, da Constituição Federal, assegura aos trabalhadores domésticos os direitos ali enumerados. No entanto, em instante algum, veda a utilização de outros que os nãoconstantes do rol. Tanto isto é verdade, que ao trabalhador doméstico não é vedada a utilização da prescrição bienal prevista no art. XXIX, do art. $7^{\circ}$ não constante da relação. Não se diga aqui não estamos diante de um direito e que, portanto. este poderia ser estendido. Ora, se é possível estender-se uma restrição a direito (como é o caso do decurso do prazo prescricional), com muito mais razão é possível a extensão de direitos, se as situações forem semelhantes. Não se diga que a doméstica, ao realizar trabalho no âmbito doméstico para empregadores sem fins lucrativos, teria em seu desfavor um fator discrimen que ampara a distinção. Ora, a situação do empregador é elemento externo que não ampara a distinção, além do que há que se confrontar a premissa: será que do trabalho da doméstica o empregador não retira alguma utilidade lucrativa ainda que imediata. Ora, se alguém não tem que se ocupar da casa, pode - e isto ocorre em geral estar trabalhando fora do lar e percebendo alguma vantagem econômica deste fato. 
Logo, embora a utilidade econômica indireta esteja presente não é considerada para fins de direitos para a doméstica, o que, parece-nos, revela-se como um contra-senso. Portanto, desde que revele vantagem econômica indireta, algumas das vantagens do trabalhador em geral pela identidade de situações - deve ser estendida, sob pena de afronta ao princípio da isonomia, também à doméstica. Logo, mesmo que não contemplada imediatamente na relação do par. único do art. $7^{\circ}$. seria possível, no caso concreto e em nome da isonomia (fundamento da razoabilidade como já visto). da extensão de direitos sociais à doméstica como, v.g., o pagamento de horas-extras. Perceba-se que, em nome da razoabilidade, é possível a extensão de direitos sociais para situações originariamente não-previstas constitucionalmente, mas não-proibidas, como forma de se evitar atentado ao princípio da isonomia. A extensão evita mesmo a distorção do sistema e a solução desprovida de razoabilidade. Aliás, estas digressões merecem ser mantidas mesmo com o advento, no mundo jurídico da Lei n. I.1324/06, onde alguns direitos passaram a ser previstos expressamente para os casos das domésticas.

3) Falta de regulamentação para a hipótese prevista na Constituição

a) Da mesma forma, algumas das hipóteses se repetiram entre as propostas dos alunos. Alguns dos exemplos foram de Direito da Seguridade Social (como no caso da dependência e do beneficio assistencial do art. 203, inciso V, da Constituição Federal, regulamentado pela Lei Orgânica da Assistência Social LOAS). Interessante, ainda, a preocupação constante com a dispensa arbitrária e aquela por motivos de automação, que não teriam sido regulamentadas por legislação posterior. De uma forma geral, percebeu-se a necessidade da construção de postulados de razoabilidade e proporcionalidade para a consolidação da proteção prevista constitucionalmente. A falta de regulamentação e as sugestões propostas com base nos conceitos, por exemplo, da própria doutrina e de uma análise mais cuidadosa da letra da Lei e das limitações impostas pelo art. 10, inciso 1, Ato das Disposições Constitucionais 
Transitórias - remontaram à necessidade de se dar efetividade à norma constitucional, sob pena de perda de sua força normativa. Há que se ressaltar que, no caso do art. $7^{\circ}$, inciso I, da Constituição Federal, a utilização da indenização prevista no art. 10. I, ADCT. revela a indevida patrimonialização dos direitos humanos. No lugar da garantia de emprego prevista constitucionalmente (relação de emprego garantida contra despedida arbitrária), há a inadequada transformação de uma questão referente a direitos humanos em direito a compensação financeira. Nem se diga que o próprio texto do art. $7^{\circ}$ inciso I, da CF, prevê uma indenização compensatória. Esta indenização não pode substituir o Direito em si mesmo, que é fundamental. Além disto, a transformação de uma disposição de caráter transitório em definitiva conspira contra a própria força normativa da Constituição, já que a proteção é ao emprego, sendo a indenização, em si. não é o Direito - mas a reparação em caráter complementar.

b) A proteção em face da automação também mereceria maior cuidado dos juslaboralistas, já que não pode ser inviabilizada por falta de regulamentação (art. $7^{\circ}$, inciso XXVII). Não nos parece razoável que já não existam nos diversos instrumentais jurídicos do Direito do Trabalho elementos suficientes para delimitar o nível desta proteção. Aliás. bastaria verificar-se no extenso rol de convenções coletivas de trabalho como vem se dando esta proteção para que ela tomasse conta, enquanto expressão de interpretação evolutiva. da atuação do Judiciário.

4) Questões procedimentais que efetivam os direitos sociais em geral. e os trabalhistas em particular

a) Como já dito, não basta existir uma interpretação que evolua no sentido do Direito material, se o mesmo não se der no plano procedimental. Realizada pelo Judiciário - entendido no sentido amplo proposto -, a interpretação evolutiva pressupõe a maximização de resultados pelo processo. A instrumentalidade nada mais é do que expressão da razoabilidade no processo. Portanto. a admissão da competência da Justiça do Trabalho, por 
exemplo, para questões envolvendo acidentes do Trabalho, por si só, revela involução nos destinos do Direito. Além do conspirar contra a própria leitura do art. 109, inciso 1, da Constituição Federal, revela um retrocesso. A Justiça Estadual, completamente equipada e habilitada a dizer sobre o tema. é preterida por ramo da jurisdição, que deverá realizar profunda adaptação à nova lide. Por outro lado, se a questão fosse a da substituição por um ramo mais protecionista do trabalhador do que a Justiça Estadual, estariamos diante de uma evolução. No entanto, nem isto se apresenta. Dos processos que. nesta matéria foram decididos pela Justiça do Trabalho, tem-se a notícia de que houve a aplicação da prescrição bienal, mais desfavorável, da Justiça do Trabalho. Pouco razoável, utilizar-se de norma, ainda que processual, menos protetiva do trabalhador mormente em uma Justiça conhecida, ainda que esta premissa esteja sofrendo injunções com a onda flexibilizatória, pela proteção ao trabalhador pelas premissas do Direito Trabalhista. Os mesmos motivos nos levam a crer no afastamento da lei trabalhista para as prescrições em casos de indenização civil decorrente de acidente do trabalho - aqui a competência já foi firmada pelo Judiciário, com base na Emenda Constitucional n. $45 / 04$. Interessante reparar que a norma trabalhista menos protetiva, no nosso entender, jamais poderia ser estendida interpretação involutiva. Ressalte-se, aqui, a falta de razoabilidade descrita pelos próprios alunos: "a prescrição bienal que tem sido adotada pelos Juízos trabalhistas não leva em conta que algumas seqüelas decorrentes tais situações demoram mais que dois anos para se manifestar"

b) A busca da atuação do Ministério Público em casos envolvendo interesses individuais homogêneos que revelam maior interesse social deflui da própria Constituição e da essência do que representa a atuação desta entidade. Quanto mais o trabalhador puder ser protegido por entidades ligadas a interesses coletivos e públicos (sindicatos e Ministério Público), mais os direitos sociais serão protegidos. $O$ trabalhador, individualmente considerado, se encontra, em várias situações, refém da situação 
de opressão durante o curso da relação empregaticio. Nestes casos. técnicas que envolvam uma revisão do decurso do prazo prescricional ou mesmo da atuação de entes de representação coletiva ou social revelam-se enormemente favoráveis à consolidação dos direitos fundamentais sociais. Perceba-se que. em alguns casos. embora aparentemente o interesse protegido é individual homogêneo, na realidade, está a ocultar um interesse reflexo de natureza social (portanto, coletivo ou difuso mesmo). Logo, perfeitamente possível a legitimação de entidades como sindicatos e Ministério Público. Possibilitar-se a atuação destes entes, nestes casos, representa uma efetivação instrumental no sentido da evolução dos direitos sociais.

c) Ainda nas situações envolvendo direitos sociais, ainda que exercitáveis pela via individual, parece-nos um retrocesso impingir-se aos atores envolvidos, em especial aos reclamantes, ônus extremamente excessivos. Assim ì o caso citado pelos discentes de "imposição ao reclamante do encargo de apresentar o correto endereço das impresas fornecedoras de mão de obra em relação terceirizada de trabalho"

6. A razoabilidade como método para leitura dos direitos sociais: uma conclusão

Como visto, mais do qualquer outra coisa a utilização do postulado da razoabilidade se apresenta como método para a leitura dos direitos sociais em geral, e dos trabalhistas em particular.

Temos perccbido que o mútodo de leitura da ciência jurídica é essencial para a construção de um dever-ser nas exatas proporções do que representa esta ciência. O mítodo, cremos, é tão importante quanto à questão da essência do próprio Direito. O método ligado à essência. A essência defluindo do método. Enfím, os ditames da Filosofia como os únicos em que o Direito passa a ter as suas verdadeiras soluções. $O$ resto é o resto: simples dilentantismo e, em certos casos, conjunturas não-só despropositadas, mas também mal-intencionadas. No fundo mera ignorância de uma humanidade. Um estado de trevas. em que a destruição de todos passa pela falta de senso humanitário de alguns. A humanidade que se exaure na própria pessoa não é exercício de "humanitas" mas sim uma despropositada ignorância pelo destino dos homens.

São Paulo, junho de 2006. 